\title{
Preliminary Results of Minimally Invasive Decompression, TLIF and Percutaneous Pedicle Screw Insertion in Stenotic Spondylolisthesis with Severe Facet Joint Osteoarthritis
}

\section{Eleftherios Archavlis ${ }^{1 *}$, Mario Carvi Y Nievas ${ }^{2}$ and Peter Ulrich ${ }^{1}$}

${ }^{1}$ Department of Neurosurgery, Sana Klinikum Offenbach, Akademisches Lehrkrankenhaus der Universität Frankfurt, Germany

${ }^{2}$ Department of Neurosurgery, Klinikum Frankfurt Hoechst, Akademisches Lehrkrankenhaus der Universität Frankfurt, Germany

\begin{abstract}
Object: Minimally invasive spine (MIS) procedures are increasingly being recognized as equivalent to open procedures with regard to clinical and radiographic outcomes. These techniques are also believed to result in less pain and disability in the immediate postoperative period. There are, however, little data to assess whether these procedures in combination with minimally invasive transforaminal interbody fusion (MI-TLIF) and percutaneous pedicle screw insertion are effective in complex cases of stenotic degenerative spondylolisthesis with severe facet joint osteoarthritis (FJO).
\end{abstract}

Methods: This study retrospectively reviewed all patients who underwent lumbar instrumentation, fusion and decompression for degenerative spondylolisthesis with severe stenosis and facet joint osteoarthritis (FJO) between June 2010 and June 2011. Blood loss, operative time and intraoperative complications were assessed in all surgically treated patients who were treated with MIS decompression, MI-TLIF and percutaneous transpedicular instrumentation. Clinical outcome was measured using the Oswestry Disability Index (ODI) and Visual Analogue Scale (VAS) for back pain, leg pain, and activity level. Satisfaction was assessed with VAS for satisfaction. Radiological follow-up includes x-ray films, computed tomography and in some cases magnetic tomography scan.

Results: Twenty four cases with severe stenotic changes accompanied by severe FJO were treated with minimally invasive procedure. The minimum follow-up was 6 months with a mean of 8 months. The mean preoperative ODI score was 46.8 , decreasing to a mean of 23 postoperatively. The mean VAS leg and back pain scores were 67.5 improving to means of 25.8. Twenty one out of 24 cases experienced a clinical benefit according to VAS for satisfaction and ODI. Complications included wound healing disturbance (4\%), CSF fistula (4\%) and contralateral radiculopathy due to articular bone spurs (8\%). The accuracy of pedicle screws was high and only one revision surgery was performed.

Conclusion: MIS for severe stenotic spondylolisthesis leads to adequate and safe decompression of lumbar stenosis and results in a highly significant reduction of symptoms and disability. MIS-TLIF and percutaneous pedicle screw insertion constitute a promising treatment alternative for patients with severe stenosis and facet joint osteoarthritis.

Keywords: Minimally invasive transforaminal interbody fusion; Spondylolisthesis; Lumbar stenosis; Facet joint osteoarthritis

Abbreviations: CSF: Cerebrospinal Fluid; CT: Computerized Tomography; EBL: Estimated Blood Loss; FJO: Facet Joint Osteoarthritis; LBP: Low Back Pain; MR: Magnetic Resonance; MIS: Minimally Invasive Surgery; MI-TLIF: Minimally Invasive Transforaminal Interbody Fusion; SD: Standard Deviation; VAS: Visual Analog Scale

\section{Introduction}

A basic principle of minimally invasive spine surgery (MIS) is to effectively treat pathology with minimal disturbance of normal anatomy, although some reports suggest that the limited exposure that results from these techniques can result in incomplete treatment of pathology with no clear-cut advantage over traditional techniques $[1,2]$. The avoidance of complications is more challenging through limited surgical portals [1]. Failure surgery and reoperation rates can increase, especially in the field of lumbar instrumentation [3,4]. In spite of these challenges, the evolution of MIS has exceeded that of traditional spine procedures over the past 2 decades [5-10].

The area of greatest controversy, however, is the handling of cases with degenerative spondylolisthesis with severe stenosis of the spinal canal [11]. The presence of severe arthritic changes of the facets is characteristic in many of these patients [12]. Some authors prefer to perform a laminectomy without fusion. It is argued that fusion after laminectomy is necessary to prevent instability and postoperative complications [13]. Some authors prefer the open interbody fusion and instrumentation in cases of spondylolisthesis with severe stenosis and spondylarthrosis [13-15]. There is growing evidence that circumferential support through TLIF offers the advantage of avoiding the cost and morbidity of an anterior approach while providing equivalent clinical results with a lower rate of perioperative complications than PLIF [16]. Several studies have reported the favorable outcomes of MI-TLIF accompanied by spinal instrumentation with percutaneous pedicle screw insertion and decompression in degenerative spondylolisthesis $[9,10,14,17]$. In the presence of severe spinal canal stenosis and distorted facet anatomy due to severe FJO, MIS techniques however could limit direct visualization of neural elements and pedicle screws relative to key anatomical structures and could increase the rate of complications and pedicle screw misplacement. Hsieh et al. reported the feasibility of MIS in several cases of complex spinal disorders such as spinal

${ }^{*}$ Corresponding author: Eleftherios Archavlis, Department of Neurosurgery, Sana Klinikum Offenbach, Akademisches Lehrkrankenhaus der Universität Frankfurt Starkenburgring 66, 63069 Offenbach, Germany; Tel: 0049178 9160743; Fax 0049698405 3143; E-mail: neurosurgery@t-online.de

Received August 26, 2013; Accepted September 27, 2013; Published September 30, 2013

Citation: Archavlis E, Carvi y Nievas M, Ulrich P (2013) Preliminary Results of Minimally Invasive Decompression, TLIF and Percutaneous Pedicle Screw Insertion in Stenotic Spondylolisthesis with Severe Facet Joint Osteoarthritis. Spine S5: 004. doi:10.4172/2165-7939.S5-004

Copyright: (c 2013 Archavlis E, et al. This is an open-access article distributed under the terms of the Creative Commons Attribution License, which permits unrestricted use, distribution, and reproduction in any medium, provided the original author and source are credited. 
trauma, spinal deformities, and spinal oncology [18]. Some previous studies report that MIS techniques may achieve superior clinical results with reduced postoperative pain, narcotic use, and hospital length of stay, however, the impact of MIS on outcome for the more complex degenerative spondylolisthesis cases is not yet well studied $[19,20]$.

The aim of the present study was to report data pertaining to MIS decompression, MI-TLIF and percutaneous pedicle screw insertion in spondylolisthesis with severe stenosis and FJO, with particular focus on short term results, accuracy of pedicle screw insertion and incidence of complications.

\section{Methods}

\section{Patient population}

We conducted a retrospective analysis of prospectively collecting data from consecutive patients at a single center (Sana Klinikum Offenbach, University of Frankfurt) who underwent single-level percutaneous pedicle screw insertion, MIS-decompression and TLIF, between June 2010 and June 2011, with the following inclusion criteria: 1) symptoms of neurogenic claudication or radiculopathy or incapacitating back pain refractory to adequate conservative treatment; 2) degenerative spondylolisthesis Meyerding grades I-II (Meyerding classification [21]); 3) FJO Pathria Grade 3 (Pathria et al. [8] ); 4) spinal stenosis at the affected level grade $\mathrm{C}$ and $\mathrm{D}$ (Schizas et al. [9] ).

A total of 24 patients fulfilled the inclusion criteria of our study and all patients completed the follow-up visit. Symptoms were considered refractory to non surgical management if conservative measures, particularly non-steroidal anti-inflammatory drug and physical therapies, had been administered for at least 2 months without sufficient improvement. The severity of vertebral displacement was estimated according to the grading criteria of Meyerding [21]. The fourpoint scale that Pathria devised for radiographic grading FJO was used to delineate the severity of facet disease [8]. Radiographically, normal facets were classified as grade 0 . Facets with joint space narrowing were classified as grade 1, facets with narrowing plus sclerosis or hypertrophy as grade 2, and facets with severe degenerative disease encompassing narrowing, sclerosis, and osteophytes as grade 3 . The severity of lumbar spinal stenosis at the affected level was based on the morphology of the dural sac on magnetic resonance images according to Schizas et al., who described a 7-grade classification based on the morphology of the dural sac as observed on T2 axial magnetic resonance images based on the rootlet/cerebrospinal fluid ratio. Grades A and B show cerebrospinal fluid presence while grades $\mathrm{C}$ and $\mathrm{D}$ show none at all [9].

Contraindications for the minimally invasive approach (and the patients with these contraindications were treated by traditional open surgery) included 1) the patients with high-grade (grade III/IV) spondylolisthesis, 2) the patients who needed multi-level decompression and fusion, 3 ) the patients with combined coronal and/ or sagittal deformities (kyphoscoliosis) that needed a correction, and 4) the patients who had back disease involving trauma, infection or other pathologic causes.

Neither lateral and foraminal stenosis nor segmental instability were considered as contraindications for MIS.

\section{Preoperative assessment}

All patients underwent a standardized neurological and clinical assessment to evaluate walking distance, pain was measured separately for the low back and the legs according to a self-assessment on a 100$\mathrm{mm}$ horizontal line with 0 equal to "no pain," and 100 equal to "very severe pain" [10]. Disability was assessed using the Oswestry Low Back Pain Disability Questionnaire (ODI), which has been validated and reported on for German-language speakers. The ODI was scored on a $0-100$ scale, $0-20$ equates to minimal disability, 20-40 moderate disability, 40-60 severe disability, $60-80$ crippled, and $80-100$ bedbound or exaggerating.

To evaluate neurologic deficit, we analyzed this parameter on a 3-point scale, absent (without motor or sensory deficit), mild (motor deficit grade 4 or sensory deficit) and severe (motor deficit grade $0-3$ ).

Radiological/neuroimaging work-up included MR imaging, myelography, and postmyelography CT scanning for identification of the involved segments.

\section{Assessment of intraoperative parameters}

Intraoperative parameters such as duration of the procedure, Estimated Blood Loss (EBL), and intraoperative complications (for instance, incidental durotomy) were analyzed on the basis of operative records.

\section{Surgical Technique of percutaneous instrumentation, MAST- decompression and TLIF}

Surgical access for interbody fusion was obtained using a tubular retraction system (Quadrant, Medtronic Sofamor Danek). Pedicle screws and rods were placed percutaneously (CD Horizon Sextant, Medtronic Sofamor Danek). In cases that spondylolisthesis could not be reduced through distraction of the disc space, a reduction screw extender allowed for reduction. In each case the patient was positioned prone on a spinal surgery table. In some cases, positioning alone resulted in some degree of postural reduction. Intra-operative 2D $\mathrm{C}$-arm guidance was integrated with navigation software (2D Fluoro navigation, Brainlab) and enabled the surgeon to navigate relative to preoperative $\mathrm{CT}$ data after registration and matching with intraoperative two plane fluoroscopy. For that purpose, a reference pin kit was placed at the spinal process of the affected vertebra, through a $1 \mathrm{~cm}$ midline skin incision on the dorsal skin surface. A detailed description of the procedure is available in the literature [16].

The site of MI-TLIF was determined according to the side of main symptomatology, the central and contralateral decompression was performed by bending the tubular retractor medially. After discectomy, the empty disc space was filled initially with Tri-Ca-Phosphate as well as local autograft, leaving a channel for an interbody implant. An appropriately sized polyetheretherketone (PEEK) interbody implant was selected and filled with autograft from the resected lamina. The implant is convex-shaped to allow reduction (Capstone, Medtronic).Of note, even in patients with Grade II spondylolisthesis, an attempt was made to fully reduce the slippage after adequate disc space distraction had been achieved. All procedures were done in a strictly standardized step-by-step fashion. All surgical procedures were performed by the same consultant neurosurgeon (EA).

All patients received a single intravenous dose of an antibiotic agent and a wound drain placed subfascial.

\section{Radiological assessment}

The accuracy of pedicle screws was estimated with postoperative CT. Evaluation of screw placement was performed according to the criteria published by Learch [22] modified to include assessment in the coronal and sagittal reformatted images [23]. A screw was classified as cortical encroachment if the pedicle cortex could not be visualized and if bone in excess of 2-mm was visible on the opposite direction. 
Citation: Archavlis E, Carvi y Nievas M, Ulrich P (2013) Preliminary Results of Minimally Invasive Decompression, TLIF and Percutaneous Pedicle Screw Insertion in Stenotic Spondylolisthesis with Severe Facet Joint Osteoarthritis. J Spine S5: 004. doi:10.4172/2165-7939.S5-004

Page 3 of 7

Frank penetration was defined when not only the cortex was invisible but also when the screw trajectory was obviously outside the pedicular boundaries. Frank penetration was further subdivided and defined as minor (less than half of the screw thread), moderate (less than the full screw thread) and severe (more than one screw diameter) [23].

Radiographic assessment of solid fusion was not performed because of the short term follow-up.

\section{Outcome assessment}

Pain (VAS score) and walking distance were recorded. Patient satisfaction was also assessed according to a self-assessment on a 100mm horizontal line with 0 to 49 equivalent to "not satisfied", 50 equal

\begin{tabular}{|c|c|c|}
\hline Parameters & - & Value \\
\hline no. of cases & & 24 \\
\hline Age (mean \pm SD) & in years & $67 \pm 8$ \\
\hline Sex (female), n (\%) & no. of cases & $14(58.3)$ \\
\hline Body mass index (mean \pm SD) & $\mathrm{kg} / \mathrm{m}^{2}$ & $28 \pm 6$ \\
\hline Standard follow up (range) & in months & $8(6-12)$ \\
\hline Spondylolisthesis Meyerding Grade & no. of cases & \\
\hline Grade 1 & & 18 \\
\hline Grade 2 & & 6 \\
\hline Level & no. of cases & \\
\hline L3-4 & & 2 \\
\hline L4-5 & & 16 \\
\hline L5-S1 & & 6 \\
\hline Duration of symptoms & in months & \\
\hline LBP & & $31 \pm 27$ \\
\hline Leg pain & & $17 \pm 9$ \\
\hline neurogenic claudication & & $15 \pm 4$ \\
\hline Symptoms & no. of cases & \\
\hline LBP & & 17 \\
\hline Leg pain & & 19 \\
\hline neurogenic claudication & & 20 \\
\hline Neurologic deficit & no. of cases & \\
\hline absent & & 15 \\
\hline mild & & 4 \\
\hline severe & & 5 \\
\hline Walking distance & no. of cases & \\
\hline$<500$ meters & & 12 \\
\hline $500-1000$ meters & & 8 \\
\hline$>1000$ meters & & 4 \\
\hline Medical history & no. of cases & \\
\hline Cardiovascular disease & & 2 \\
\hline Diabetes & & 4 \\
\hline Thromboembolism & & 1 \\
\hline Hypertension & & 6 \\
\hline $\begin{array}{l}\text { Asthma or chronic obtructive pulmonary } \\
\text { disease }\end{array}$ & & 2 \\
\hline & & \\
\hline
\end{tabular}

Table 1: Patient's characteristics. to "neither satisfied nor dissatisfied", 51-75 "satisfied", and 76 to 100 equivalent to "very satisfied". Functional disability was quantitatively measured using the Oswestry Low Back Pain Disability Questionnaire (ODI). Both the VAS and ODI were prospectively acquired. The subjective postoperative symptoms documented at each postoperative visit were divided into 4 categories: symptom free, back pain only, leg pain only and both back and leg pain. Patients presenting with significant residual or recurrent symptoms underwent postoperative MR imaging. Perioperative morbidity included reoperations within 30 days and the presence of an increased postoperative radicular deficit. In order to assess the functional outcome, we used a functional scale as described by Whitecloud et al. (excellent, good, fair and poor) [24].

Radiological and outcome assessment were performed by a single author (EA).

\section{Statistical analysis}

Statistical analysis was performed using an unpaired t-test for parametric variables. Categorical variables were analyzed in contingency tables using the Fisher exact test. Results with $\mathrm{p}<0.05$ were considered significant. All calculations were made with standard commercial software (BiAs)

\section{Results \\ Patient characteristics}

The minimal invasive procedure was performed in 24 patients. Patient characteristics, including age, sex and presence of neurologic deficits according to the primary admission diagnosis are shown in Table 1.

All patients underwent decompression at a single level. 58 percent had a left-sided and $42 \%$ had a right-sided approach. 2 patients had concomitant synovial cyst excision. $62.5 \%$ of patients $(n=15$ of 24$)$ in the study had at least 1 significant medical comorbidity. Follow-up was obtained in all patients. The overall preoperative ODI score was 46.8 .

\section{Intraoperative parameters}

The scheduled procedure was adhered to in all patients. In one case we had to change the side of MI-TLIF because of a con-joined nerve root which made the approach to the lumbar disc very difficult with high risk of neurologic deficit. The mean surgical time for the minimal invasive procedure was $230(\mathrm{SD} \pm 48)$ minutes. The EBL was 185 (SD $\pm 140) \mathrm{ml}$. One patient required a blood transfusion due to prolonged surgery. There were no conversions to an open procedure.

\section{Complications of MIS}

Complications after MAST are shown in Table 2. An intraoperative incidental durotomy occurred in $1(4 \%)$ patient. This occurred at the beginning of the authors experience with this technique. Self-closing nitinol U-clips (Medtronic, Inc., Minneapolis) were used for closing the dural tear through the MIS approach that could make a conventional microsuturing technique very difficult. Postoperative complications included 1 patient with pedicle screw misplacement with no neurologic sequelae, 1 patient with wound healing disturbance and 2 patients with contralateral foraminal encroachment syndromes due to osteophytic spurs arising from the facet joint and impinging the nerve root. There were no perioperative deaths.

\section{Outcome}

The mean VAS leg and back pain scores improved from a mean of 67.5 to 25.8, thus, MI-TLIF resulted in a significant reduction of 
Citation: Archavlis E, Carvi y Nievas M, Ulrich P (2013) Preliminary Results of Minimally Invasive Decompression, TLIF and Percutaneous Pedicle Screw Insertion in Stenotic Spondylolisthesis with Severe Facet Joint Osteoarthritis. J Spine S5: 004. doi:10.4172/2165-7939.S5-004

Page 4 of 7

\begin{tabular}{|c|c|c|c|c|c|c|c|c|}
\hline Pt. & $\begin{array}{c}\text { Initial Meyerding } \\
\text { Grade }\end{array}$ & $\begin{array}{c}\text { postoperative } \\
\text { Meyerding grade }\end{array}$ & $\begin{array}{l}\text { initial VAS } \\
\text { back/leg }\end{array}$ & $\begin{array}{c}\text { VAS back/leg at last } \\
\text { F/U }\end{array}$ & Complications & $\begin{array}{c}\text { VAS } \\
\text { satisfaction }\end{array}$ & ODI initial & $\begin{array}{c}\text { ODI at last } \\
\text { F/U }\end{array}$ \\
\hline 1 & 1 & 0 & 80 & 40 & no & 60 & 50 & 28 \\
\hline 2 & 1 & 0 & 60 & 10 & CSF fistula & 60 & 40 & 10 \\
\hline 3 & 2 & 0 & 60 & 20 & no & 90 & 45 & 20 \\
\hline 4 & 1 & 0 & 70 & 30 & no & 70 & 40 & 24 \\
\hline 5 & 2 & 1 & 70 & 30 & no & 80 & 50 & 30 \\
\hline 6 & 1 & 0 & 60 & 10 & wound healing disturbance & 60 & 40 & 10 \\
\hline 7 & 1 & 1 & 70 & 40 & radiculopathy contralateral & 50 & 50 & 24 \\
\hline 8 & 1 & 0 & 60 & 10 & no & 90 & 40 & 16 \\
\hline 9 & 1 & 0 & 70 & 50 & $\begin{array}{l}\text { revision contralateral } \\
\text { redecompression }\end{array}$ & 50 & 55 & 26 \\
\hline 10 & 1 & 0 & 80 & 10 & no & 90 & 48 & 12 \\
\hline 11 & 2 & 0 & 60 & 20 & no & 80 & 40 & 20 \\
\hline 12 & 1 & 0 & 60 & 0 & no & 90 & 44 & 24 \\
\hline 13 & 1 & 0 & 70 & 50 & revision pedicle screw & 40 & 60 & 42 \\
\hline 14 & 1 & 0 & 80 & 40 & no & 60 & 50 & 28 \\
\hline 15 & 2 & 0 & 60 & 20 & no & 90 & 45 & 20 \\
\hline 16 & 1 & 0 & 70 & 30 & no & 70 & 40 & 24 \\
\hline 17 & 2 & 1 & 70 & 30 & no & 80 & 50 & 30 \\
\hline 18 & 1 & 1 & 70 & 40 & no & 50 & 50 & 24 \\
\hline 19 & 1 & 0 & 60 & 10 & no & 90 & 40 & 16 \\
\hline 20 & 1 & 0 & 70 & 50 & no & 50 & 55 & 26 \\
\hline 21 & 1 & 0 & 80 & 10 & no & 90 & 48 & 12 \\
\hline 22 & 2 & 0 & 60 & 20 & no & 80 & 40 & 20 \\
\hline 23 & 1 & 0 & 60 & 0 & no & 90 & 44 & 24 \\
\hline 24 & 1 & 0 & 70 & 50 & no & 40 & 60 & 42 \\
\hline
\end{tabular}

Table 2: Initial and Follow-up Radiographic/Clinical Data.

overall pain $(\mathrm{p}<0.001)$. Differentiating between low back pain and leg pain revealed no differences in improvement. Neurogenic claudication improved in $91 \%$ of the patients $(\mathrm{p}<0.001)$. Walking distance varied greatly among individual patients, but overall ambulation recovered significantly from a mean of $250(\mathrm{SD} \pm 200)$ to a mean of $3100(\mathrm{SD} \pm$ 3540) $(\mathrm{p}<0.001)$.

Average clinical improvement in ODI was $50.8 \%$ for the entire cohort $(46.8 \%$ before surgery to $23 \%$ after surgery) at a mean of 8 months follow-up (range $6-12$ ), demonstrating a marked and significant improvement $(\mathrm{p}<0.001)$.

Overall, $79.8 \%$ patients were satisfied (60.7\% very satisfied, $9 \%$ satisfied) with their treatment; $12.7 \%$ were dissatisfied and $9.5 \%$ were neither satisfied nor dissatisfied. Twelve out of 24 showed no symptoms at the final follow-up. Additionally, 19 patients (85\%) showed excellent or good results according to the functional scale.

\section{Radiology}

There were 18 patients who had a grade I spondylolisthesis and 6 with grade II. The slip was anatomically reduced in grade I patients by $100 \%$ in 15 patients and between $90 \%$ and $95 \%$ in 3. In grade II, $100 \%$ anatomical reduction was achieved in 4 patients and between $90 \%$ and $95 \%$ in 2 patients.

In the axial and coronar images, one screw showed frank pedicle penetration laterally, classified as severe and produced clinical symptoms of progressive low back pain. Revision surgery was performed 2 weeks later. Eight screws encroached the pedicular cortex without frank penetration ( 3 medially, 4laterally, 1 cranially).

The patient with franc penetration made an uneventful recovery. This case was not encountered in the beginning of our learning curve but on our thirteenth procedure.
No evidence for loss of correction was observed in the follow-up.

As mentioned above we avoid intentionally to report about radiographic solid fusion rates because of the short term follow up.

\section{Revision rate}

The revision rate at a mean of 6 months (range, 3 - 8 months) from surgery was $10 \%$, which included either repeat decompression alone $(\mathrm{n}=1)$ or pedicle screw revision $(\mathrm{n}=1)$.

Two patients complained about contralateral neuropathic pain after surgery. Postoperative CT scanning demonstrated sufficient decompression of the central stenosis, however, newly emerged osteophytic spurs arising from the facet joint and impinging the nerve root was made responsible for the contralateral foraminal encroachment. We performed repeat decompression in one patient, and percutaneous periradicular nerve root infiltration therapy in the other, both of which had complete permanent resolution of symptoms.

Before revision, the revised patients $(n=2)$ had an ODI that was $57.5 \%$. For these patients the mean ODI preoperative was $42.5 \%$. Following revision, these patients had a mean ODI of $34 \%$ at their latest follow-up

\section{Discussion}

Decompression, stabilization and fusion are known to be effective in degenerative spondylolisthesis [13]. In current surgical practice, the majority of patients with degenerative spondylolisthesis undergo an instrumented fusion [15]. In the recently reported spine patient outcomes research trial (SPORT) on degenerative spondylolisthesis only $5 \%$ of patients underwent decompression alone [15]. Based on the available literature, fusion in this population is supported, however, not absolute [11]. There is controversy concerning the surgical approach in 
order to achieve fusion and the necessity of MIS procedures $[4,9,11]$. Because of a reduced destruction of the soft tissues, proponents of these MIS techniques claim to achieve superior clinical results with reduced postoperative pain, narcotic use, and hospital length of stay [1]. On the other hand, performing percutaneous instrumentation, fusion and decompression in complex cases with severe arthritic and stenotic changes could increase the complication rate and lower the accuracy of pedicle screw insertion [18]. We performed the current analysis to evaluate feasibility and to provide data for complication rates in these patients.

Degenerative spondylolisthesis often coincides with other consequences of spinal degeneration such as spinal stenosis, disc prolapse and instability, facet joint arthritic changes, resulting in a heterogeneous patient population [12]. Moreover the severity of the central spinal stenosis, facet osteoarthritis and foraminal narrowing can significantly differ between patients [17]. Consequently, it has been suggested that the procedure should be tailored to each patient depending on imaging findings and symptoms-for example, ventral approaches in cases of high grade spondylolisthesis or unilateral approaches in cases of unilateral symptoms $[13,16]$. The authors of previous studies of MIS and especially MI-TLIF have commonly neglected the heterogeneity of the patient population by including such complex cases in the patient population without differentiating the efficacy of the surgery on these patients $[9,15,25]$. Other authors either a priori excluded such complex cases from performing MIS techniques or recommended that MIS should be performed at the discretion of the surgeon [2]. This may, of course, reflect the patient's individual situation, but it prevents the drawing of solid conclusions regarding the efficacy of MIS techniques in comparison to open procedures.

In order to minimize the heterogeneity of the patient population, only high grade FJO (Pathria grade 3 ) and high grade spinal stenosis (grade $\mathrm{C}$ and $\mathrm{D}$ according to Schizas et al.) were included in this study. High grade spondylolisthesis was excluded in the present study.

\section{Intraoperative parameters}

Open TLIF is considered a simple and fast fusion technique, whereas MI-TLIF, especially in spondylolisthesis with severe FJO could be associated with technical challenges and longer operative duration. Weinstein et al reported by the SPORT study an operative duration of 210.4 ( $\mathrm{SD} \pm 81.1$ ) minutes. In our study, the duration of surgery was proved to be $230(\mathrm{SD} \pm 48)$ minutes which was comparable with the time described in the SPORT study. Concerning blood loss in open TLIF, Weinstein et al reported $569.2(\mathrm{SD} \pm 425.4) \mathrm{ml}$, requiring transfusion in 62 of the 178 cases in the randomized cohort (35\%). It is of note that $27 \%$ of the randomized control group of the SPORT study received a multilevel fusion [15]. While in this study we evaluated only a single level fusion, all cases included were demanding because of the high grade of stenosis and FJO. This, however, did not translate in excessive operative time, EBL or perioperative morbidity. Blood loss was clinically insignificant $(185 \pm 210)$, requiring transfusion in only one case.

\section{Complications and reoperations}

The authors of comparative studies involving open and MIS techniques for interbody fusion have reported complication rates that were comparable but the sizes of populations have been small and the studies were mostly retrospective or lacked a control group [3,5,7,14,26]. A quantitative meta-analysis of $\mathrm{Wu}$ et al. revealed similar fusion and complication rates [27] but in some studies of less invasive techniques, however, investigators revealed an increase in perioperative morbidity, namely neurological sequelae [6] or contralateral radiculopathy although the proportion of complications war comparable Therefore, the main concern of spine surgeons in view of MIS techniques has been an increased rate of neural injury. In the series reported by Schwender et al., a postoperative increased radicular deficit was observed in 2/49 cases (4.1\%) of MIS decompression and interbody fusion cases (one from graft dislodgement, the other from contralateral neuroforaminal stenosis) [17]. According to our data, actual injury to a nerve root did not occur. Intraoperative manipulation and/or compression of nerve roots, however, may provoke radicular deficit postoperatively. Weinstein et al [15] reported nerve-root injury as postoperative complication in $1 \%$ of cases. We observed in two patients, postoperatively, a contralateral foraminal encroachment syndrome due to osteophytic spurs arising from the facet joint and impinging the nerve root. We think that these patients with high grade FJO might have a higher risk of postoperative foraminal encroachment contralateral to the decompression entry. Larger series are needed to further evaluate this matter. In our opinion, a bilateral facetectomy through a MIS approach should be done in selected cases.

Unintended durotomy is another concern during spinal decompressive procedures, although no association with long-term sequelae has been found. Overall, durotomy rates for laminectomy have been shown to range from 5 to $15 \%$. This rate is reported $(11 \%)$ by SPORT study for spinal stenosis and degenerative spondylolisthesis where conventional open techniques were performed for the majority of patients [15]. The results of the present study, namely $4 \%$ are underscoring that MI-TLIF and MIS decompression through a unilateral approach although technically demanding, carry a low risk of unintended durotomy.

Potter at al. demostrated a wound infection rate of approximately $2 \%$ in open TLIF cases [12], and this complication was also rare in our study with $4 \%$. As far as the accuracy of pedicle screws is concerned, in a study of computer tomography assessment of percutaneous pedicle screw insertion, Schizas et al. reported an overall rate of screw perforation of $30 \%$ with an incidence of severe frank pedicle penetration of $3.3 \%$ as seen on axial and coronar images. $13 \%$ of the patients $(2 / 15)$ had severe frank penetration from the screws, while $80 \%$ of them $(12 / 15)$ had some perforation [22]. Schwender et al. reported screw malposition requiring repositioning in $2 / 49$ (4.1\%) [17]. In the present study, we found a severe frank pedicle penetration of $1 \%(1 / 96)$ of all pedicle screws. $4 \%$ of our patients $(1 / 24)$ had severe frank penetration from the screws, while $50 \%$ of them $(12 / 24)$ had some perforation. The low frank penetration rate in our study may be partly due to the use of cannulated pedicle screws and computer-assisted image guidance. We used in particular, the more recent ability to fuse preoperative CT scans with intraoperative fluroscopic imaging.

In the recently reported SPORT study on surgical versus nonsurgical treatment of degenerative spondylolisthesis, Weinstein et al. reported an overall revision rate of $12 \%$ of the surgically treated group at 2 years [15]. Within the methodological limitations of historical comparisons, and the fact that we demonstrate preliminary results after 8 months, the surgical revision rate in our study of $8 \%$ seems comparable to the SPORT study.

In summary, the MI-TLIF in complex and surgically demanding cases was neither associated with an increased rate of postoperative nerve deficits nor a high rate of other complications.

\section{Outcome assessment}

Literature analysis of open interbody fusions by using metaanalysis 
or Cochrane Review proved very challenging because measuring outcomes in musculoskeletal disorders is extremely problematic [13] and outcome variables as well as definition of (good/bad) outcome varied considerably among studies $[14,15,25]$. In the present study, analysis of outcome was based on the VAS for pain and satisfaction and the ODI for disability. MI-TLIF resulted in a significant reduction of overall pain $(\mathrm{p}<0.001)$.

In the recently reported SPORT study, Weinstein et al. reported absolute improvements of $30 \%$ in scores of back pain and $43 \%$ in scores for leg pain (on 7-point scale) which remained for 4 years after surgery [15]. These results are similar to the improvements of $61.4 \%$ and $61.5 \%$ (on VAS scale), respectively seen in our study at 8 months.

In a retrospective study, Park et al., found excellent or good outcomes after 36.1 months in $88 \%$ of their 24 patients [1]. In the present study, the rate of patient satisfaction, and improvement of neurogenic claudication after MI-TLIF was $79.8 \%$, and the rate of excellent or good functional outcome was $85 \%$ which are in accordance with that reported from the abobe authors.

The SPORT study reported significant clinical improvements in the ODI scores, in the randomized and observational cohorts combined, from 42.6 preoperatively to 20.7 in the last follow-up. These results were stable and maintained over the period of 4 years [15]. When compared with our study group similar ODI scores both before and after surgery were found $(46.8-23)$.

This study demonstrates that in selected patients with low- and midgrade degenerative spondylolisthesis accompanied by severe stenosis and FJO, MIS decompression and MI-TLIF can achieve significant improvement in functional outcome and excellent patient satisfaction in the majority of patients, in the short term.

\section{Weaknesses}

The main weaknesses of this study are inherent to its retrospective nature (i.e., selection bias and limited cohort with no control group). However, this series represents consecutive patients, with prospective data collection and $100 \%$ follow-up. The follow-up from the time of surgery was short (8 months), thus, no conclusions can be drawn about fusion rates and adjacent level disease. This study presents preliminary results and continued follow-up is mandatory and will be pursued in order to assess the long-term results. Prospective randomized trials could better address these issues.

\section{Conclusions}

MIS for severe stenotic spondylolisthesis leads to adequate and safe decompression of lumbar stenosis and results in a highly significant reduction of symptoms and disability. Early outcome and radiologic result after MI-TLIF and percutaneous pedicle screw insertion was comparable with that after conventional techniques and showed acceptable complication rates. Long term results and randomized studies could help in verifying our findings.

\section{Disclosure}

The authors report no conflict of interest concerning the materials and methods used in this study or the findings specified in this paper.

\section{References}

1. Park Y, Ha JW, Lee YT, Oh HC, Yoo JH, et al. (2011) Surgical outcomes of minimally Invasive transforaminal lumbar interbody fusion for the treatment of spondylolisthesis and degenerative segmental instability. Asian Spine J 5: 228236 .
2. Salehi SA, Tawk R, Ganju A, LaMarca F Liu JC, et al. (2004) Transforaminal lumbar interbody fusion: surgical technique and results in 24 patients. Neurosurgery 54: 368-374

3. Mummaneni PV, Rodts GE Jr (2005) The mini-open transforaminal lumbar interbody fusion. Neurosurgery 57: 256-261.

4. Rosenberg WS, Mummaneni PV (2001) Transforaminal lumbar interbody fusion: technique, complications, and early results. Neurosurgery 48: 569-574.

5. Holly LT, Schwender JD, Rouben DP, Foley KT (2006) Minimally invasive transforaminal lumbar interbody fusion: indications, technique, and complications. Neurosurg Focus 20: E6.

6. Hsieh PC, Koski TR, Sciubba DM, Moller DJ, O'Shaughnessy BA, et al. (2008) Maximizing the potential of minimally invasive spine surgery in complex spinal disorders. Neurosurg Focus 25: E19.

7. Oppenheimer JH, DeCastro I, McDonnell DE (2009) Minimally invasive spine technology and minimally invasive spine surgery: a historical review. Neurosurg Focus 27: E9.

8. Pathria M, Sartoris DJ, Resnick D (1987) Osteoarthritis of the facet joints: accuracy of oblique radiographic assessment. Radiology 164: 227-230.

9. Schizas C, Theumann N, Burn A, Tansey R, Wardlaw D, et al. (2010) Qualitative grading of severity of lumbar spinal stenosis based on the morphology of the dural sac on magnetic resonance images. Spine (Phila Pa 1976) 35: 19191924.

10. Scott J, Huskisson EC (1976) Graphic representation of pain. Pain 2: 175-184

11. Park P, Foley KT (2008) Minimally invasive transforaminal lumbar interbody fusion with reduction of spondylolisthesis: technique and outcomes after a minimum of 2 years' follow-up. Neurosurg Focus 25: E16.

12. Potter BK, Freedman BA, Verwiebe EG, Hall JM, Polly DW Jr, et al. (2005) Transforaminal lumbar interbody fusion: clinical and radiographic results and complications in 100 consecutive patients. J Spinal Disord Tech 18: 337-346.

13. Gelalis ID, Arnaoutoglou C, Christoforou G, Lykissas MG, Batsilas I, et al. (2010) Prospective analysis of surgical outcomes in patients undergoing decompressive laminectomy and posterior instrumentation for degenerative lumbar spinal stenosis. Acta Orthop Traumatol Turc 44: 235-240.

14. Dhall SS, Wang MY, Mummaneni PV (2008) Clinical and radiographic comparison of mini-open transforaminal lumbar interbody fusion with open transforaminal lumbar interbody fusion in 42 patients with long-term follow-up. J Neurosurg Spine 9: 560-565.

15. Weinstein JN, Lurie JD, Tosteson TD, Zhao W, Blood EA et al. (2009) Surgical compared with nonoperative treatment for lumbar degenerative spondylolisthesis. Four-year results in the Spine Patient Outcomes Research Trial (SPORT) randomized and observational cohorts. J Bone Joint Surg Am 91: $1295-1304$.

16. Wood MJ, Mannion RJ (2010) Improving accuracy and reducing radiation exposure in minimally invasive lumbar interbody fusion. J Neurosurg Spine 12 533-539.

17. Schwender JD, Holly LT, Rouben DP, Foley KT (2005) Minimally invasive transforaminal lumbar interbody fusion (TLIF): technical feasibility and initial results. J Spinal Disord Tech 18 Suppl: S1-6.

18. Lowe TG, Tahernia AD, O'Brien MF, Smith DA (2002) Unilateral transforamina posterior lumbar interbody fusion (TLIF): indications, technique, and 2-year results. J Spinal Disord Tech 15: 31-38.

19. Archavlis E, Carvi Y Nievas M (2013) Comparison of minimally invasive fusion and instrumentation versus open surgery for severe stenotic spondylolisthesis with high-grade facet joint osteoarthritis. Eur Spine J 22: 1731-1740.

20. Wang J, Zhou Y, Zhang ZF, Li CQ, Zheng WJ, et al. (2010) Comparison of one-level minimally invasive and open transforaminal lumbar interbody fusion in degenerative and isthmic spondylolisthesis grades 1 and 2. Eur Spine J 19 : 1780-1784.

21. Rothman RH, Simeone FA (1982) (eds.): The spine. ( $2^{\text {nd }}$ edn) WB Saunders, Philadelphia, USA.

22. Learch TJ, Massie JB, Pathria MN, Ahlgren BA, Garfin SR (2004) Assessment of pedicle screw placement utilizing conventional radiography and computed tomography: a proposed systematic approach to improve accuracy of interpretation. Spine (Phila Pa 1976) 29: 767-773. 
Citation: Archavlis E, Carvi y Nievas M, Ulrich P (2013) Preliminary Results of Minimally Invasive Decompression, TLIF and Percutaneous Pedicle Screw Insertion in Stenotic Spondylolisthesis with Severe Facet Joint Osteoarthritis. J Spine S5: 004. doi:10.4172/2165-7939.S5-004

23. Schizas C, Michel J, Kosmopoulos V, Theumann N (2007) Computer tomography assessment of pedicle screw insertion in percutaneous posterior transpedicular stabilization. Eur Spine J 16: 613-617.

24. Whitecloud TS 3rd, Davis JM, Olive PM (1994) Operative treatment of the degenerated segment adjacent to a lumbar fusion. Spine (Phila Pa 1976) 19 531-536.

25. Scheufler KM, Dohmen H, Vougioukas VI (2007) Percutaneous transforaminal lumbar interbody fusion for the treatment of degenerative lumbar instability. Neurosurgery 60: 203-212.
26. Quante M, Kesten $\mathrm{H}$, Richter A, Halm H (2012) [Transforaminal lumbar interbody fusion for the treatment of degenerative spondylolisthesis]. Orthopade 41: 153162

27. Wu RH, Fraser JF, Härtl R (2010) Minimal access versus open transforaminal lumbar interbody fusion: meta-analysis of fusion rates. Spine (Phila Pa 1976) 35: 2273-2281. 